\title{
Crystallization of oxide high iron melts
}

\author{
R.I. Gulyaeva, E.N. Selivanov, N.I. Selmenskikh \\ Establishment of Russian Academy of Sciences, Institute of Metallurgy of Ural Division, Russia
}

\begin{abstract}
The data of thermal properties in terms of amorphous oxide melt of $\mathrm{FeO}_{\mathrm{x}}-\mathrm{SiO}_{2}-\mathrm{MeS}(\mathrm{Me}-\mathrm{Cu}, \mathrm{Zn})$ system are presented in the article, temperature devitrifications of solid phase crystallization and melting are determined. Initial stages of crystal structure generation in terms of isothermal heating of amorphous alloy at the temperature $1023 \mathrm{~K}$ depending on annealing duration are studied, phase composition and metal stay forms are determined..
\end{abstract}

\section{Introduction}

Oxide materials important for pyrometallurgical processes for production of non-ferrous metals are characterized by composition complexity and apart from iron, silicon, calcium, and aluminum oxides contain impurity elements of $\mathrm{Cu}, \mathrm{S}, \mathrm{Zn}, \mathrm{Pb}$ etc. Depending on composition and cooling rate from the melted state, solid samples of oxide systems can be singled out in both crystalline and amorphous states. In is known that in oxide systems containing more than $50 \% \mathrm{SiO}_{2}$ and up to $20 \% \mathrm{Fe}_{2} \mathrm{O}_{3}$, a glassy state is formed even at a low cooling rate [1]. In articles [2, 3] it is shown that all the complex of iron silicate phases generating during sample slow cooling corresponds to a molar ratio $\mathrm{Fe} / \mathrm{Si}$ within the limits 0.9-1.6. Sample cooling with a high $(900 \mathrm{~K} / \mathrm{s})$ rate results in increase of this ratio up to 3.4. It should be noted that decrease of cooling rate results in increase of portion and size of magnetite crystals and sulfide particles. The purpose of this work is to study conditions of crystals formation from amorphous high iron oxides based on $\mathrm{FeO}_{\mathrm{x}}-\mathrm{SiO}_{2}-\mathrm{MeS}(\mathrm{Me}-\mathrm{Cu}, \mathrm{Zn})$ system as well as determination of forming phases composition.

\section{Materials and methods of study}

As an object of research an oxide sample containing mass \%: $40.5 \mathrm{Fe}, 32.1 \mathrm{SiO}_{2}, 2.4 \mathrm{~S}, 2.52 \mathrm{Cu}, 3.9 \mathrm{Zn}, 2.8 \mathrm{CaO}$, $0.8 \mathrm{MgO}, 2.6 \mathrm{Al}_{2} \mathrm{O}_{3}, 0.11 \mathrm{Sb}, 0.52 \mathrm{~Pb}, 0.12 \mathrm{As}$ was taken. Correlation $\mathrm{Fe}^{3+} / \mathrm{Fe}^{2+}$ in the sample made up 0.12 . Research sample was melted in the furnace at the temperature $1520 \mathrm{~K}$ and cooled down using the method of water granulation. As a result of cooling granular material with the size of particles $1.5-2.0 \mathrm{~mm}$ was formed. Calculation of cooling time for these particles has been performed according to equation [4]:

$\tau_{\text {cool }}=d_{d}\left(c_{p} \rho_{s l} / 6 \beta\right) \ln \left[\left(T_{m}-T_{s}\right) /\left(T_{d^{-}} T_{s}\right)\right]$, where $\tau_{\text {cool }}$ - drop solidification time;

$d_{d}$ - drop size; $c_{p}$ - heat capacity;

$\rho_{s l}$ - melt density;

$\beta$ - heat transfer coefficient melt-water factor;

$T_{m}, T_{d}, T_{s}-$ melt, drop, steam temperature.

Cooling rate of oxide melt calculated according to equation 1 is equal to $900 \mathrm{~K} / \mathrm{s}$.

The granules generated were exposed to isothermal annealing in electric resistant furnace (duration 5 and 60 minutes) at a temperature $1023 \mathrm{~K}$ in inert atmosphere.

Samples phase composition was determined using $\mathrm{X}$ ray diffractometer $\left(\mathrm{Cu}-\mathrm{K}_{\alpha}-\right.$ radiation $)$. Temperatures and heats of phase conversions are determined by means of differential-scanning calorimetry at thermo-analyzer Netzsch STA 449 C Jupiter with a heating rate 20.0 $\mathrm{K} / \mathrm{min}$ in argon current $(30 \mathrm{ml} / \mathrm{min})$. Determination of phase element composition is performed at a raster electronic microscope JSM-59000LV and energy dispersion X-ray spectrometer Oxford INCA Energy 200, samples microstructure was studied by optical microscope Olympus.

\section{Results and discussion}

Study of granular sample microstructure and phase element composition showed that its basic structural component is glass of structure $\mathrm{Fe}_{1.4} \mathrm{SiO}_{3.4}$ containing mass \%: $38.7 \mathrm{Fe}, 13.9 \mathrm{Si}, 0.8 \mathrm{~S}, 0.4 \mathrm{Cu}, 3.8 \mathrm{Zn}$. In the glass fine spherical sulfides are found $(0.5-5 \mu \mathrm{m})$ predominately bornite (Fig. 1). Non-homogeneous large sulfides $(15 \mu \mathrm{m})$ occur rarely and apart from bornite, chalkopyrite and sphalerite are detected in them. 

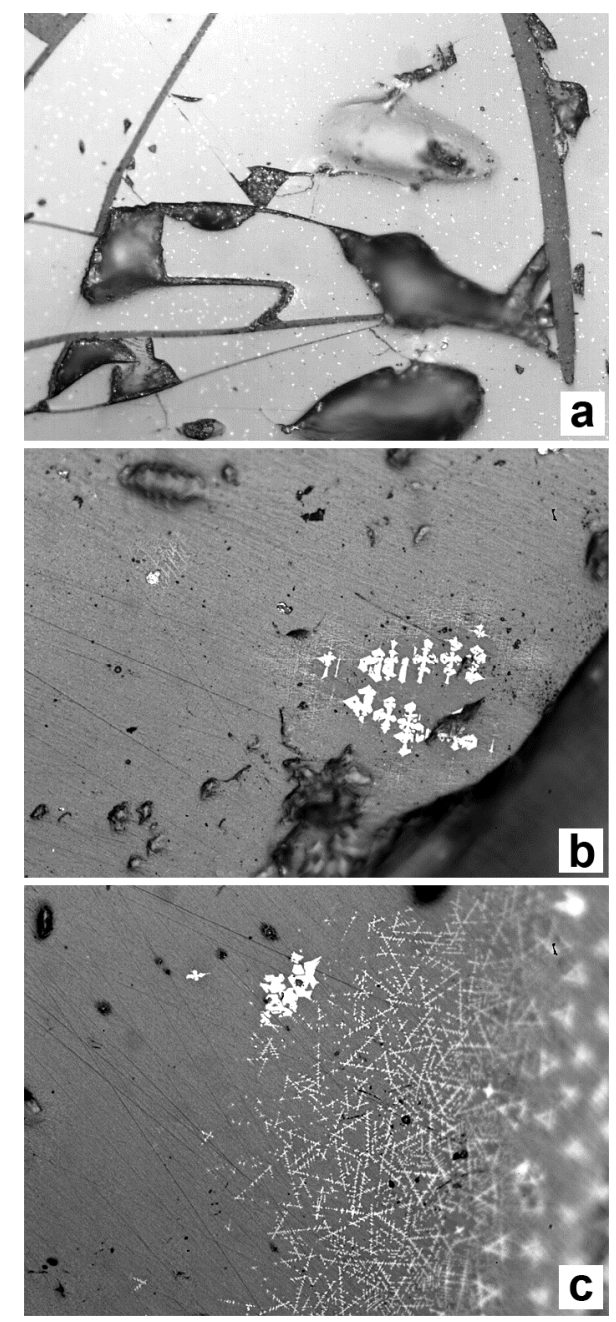

Fig. 1. Microstructure of samples cooled with the rate $900 \mathrm{~K} / \mathrm{s}$ (a) and annealed at $1023 \mathrm{~K}$ within 5 (b) and $60 \mathrm{~min}(\mathrm{c})(\mathrm{x} 500)$

X-ray analysis results showed that in terms of cooling of oxide melt with the about $900 \mathrm{~K} / \mathrm{s}$ amorphous product was formed (Fig. 2). Reflexes corresponding to crystal phase are virtually absent at diffractometer, however diffusion scattering is observed characterizing the availability of short-range order in the formed glass. Thermogram received by means of quenched sample heating is shown in Figure 3. During heating sample at heat flow curve (DSC) thermal effect is detected at $806 \mathrm{~K}$ connected with a phase transition of the second-order conditioned by devitrification process [5]. In further sample heating two exothermic heating effects with the onset/maximum at $828 / 849 \mathrm{~K}$ and $878 / 917 \mathrm{~K}$ are determined. Apparently, at these temperatures "cold" crystallization occurs i.e. formation of crystals of magnetite and silicate phase. The presence of two peaks shows that crystallization of these phases is shifted in terms of temperature. Melting of phases is accompanied by formation of two endothermic effects at 1189/1229 and 1250/1376 K. Melt crystallization temperature determined from cooling curve corresponds to $1316 \mathrm{~K}$ (Fig. 3). Temperature value and change of thermal capacity in terms of devitrification $\left(\Delta c_{p}\right)$ calculated from experimental data as well as heats of cold $\left(\mathrm{L}_{\mathrm{c} . \mathrm{cr}}\right)$ high temperature crystallization ( $\mathrm{L}_{\mathrm{h} . \mathrm{cr}}$ ) and melting $\left(\mathrm{L}_{\mathrm{m}}\right)$ of quenched sample are shown in Table 1.

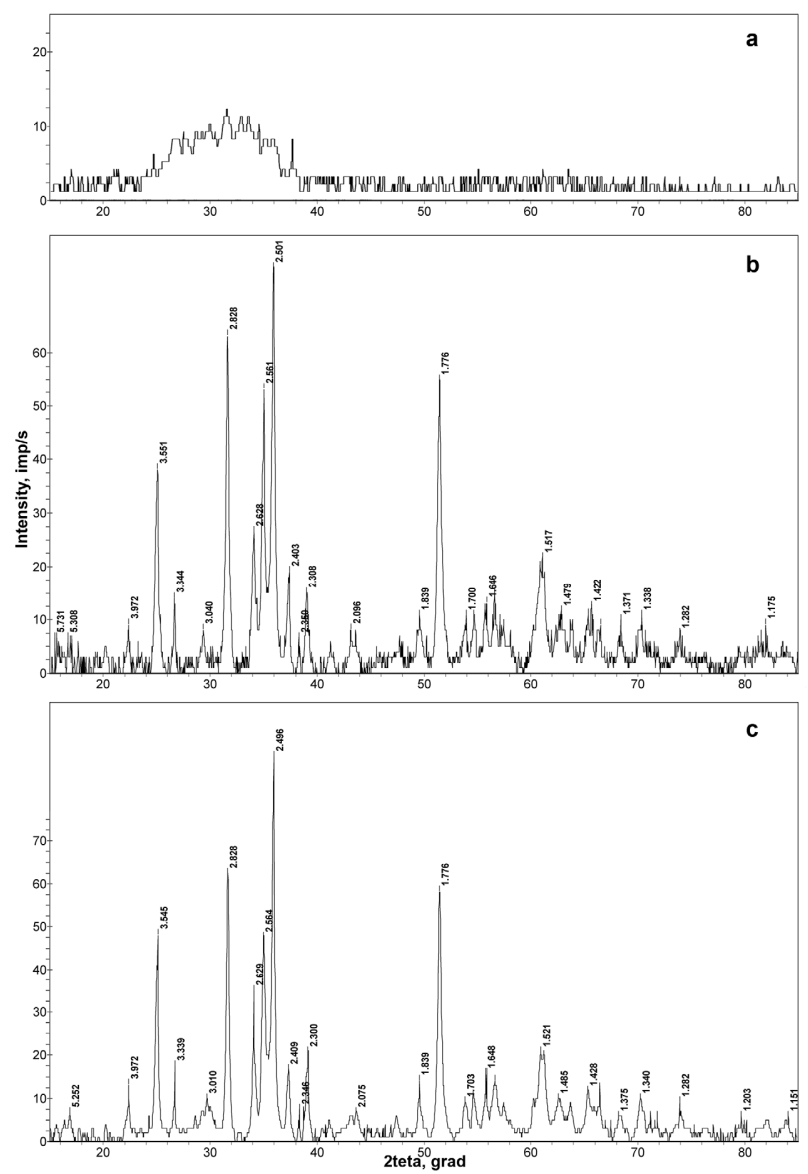

Fig. 2. X-ray spectra of samples cooled with the rate $900 \mathrm{~K} / \mathrm{s}(a)$ and annealed at $1023 \mathrm{~K}$ within 5 (b) and $60 \mathrm{~min}(\mathrm{c})$

Based on received data heating of high iron vitrified oxides up to $1500 \mathrm{~K}$ and cooling with the speed $20 \mathrm{~K} / \mathrm{min}$ results in their transition from amorphous to crystalline state. Stability factor of vitreous state is shown in the following equation [6]:

$\Delta T=T_{g}-T_{\text {c.cr },}$

where $T_{g}$ and $T_{c . c r}-$ devitrification temperatures (808 K) and onset of "cold" crystallization $(828 \mathrm{~K})$. For the sample under study $\Delta T$ value made up 22 degrees that proves non-stability of amorphous state.

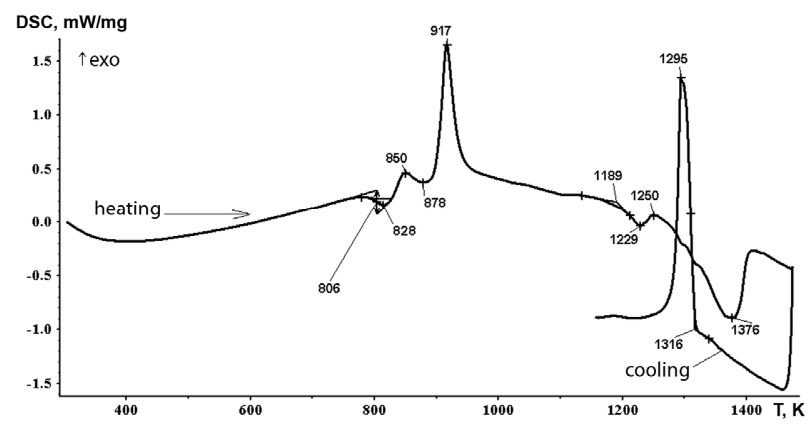

Fig. 3. Thermogram of quenched oxide sample (heating and cooling was performed at $20 \mathrm{~K} / \mathrm{min}$ in argon). 
Annealing of sample granular particles at the temperature $1023 \mathrm{~K}$ does not result in external change of their forms. The data of X-ray analysis of amorphous oxide sample after annealing with the duration of 5 and 60 min showed that the material heating results in crystalline state formation. At diffractograms (Fig. 2) reflexes of annealed samples typical for fayalite and magnetite (very weak) were detected, the intensity of them increases with the increase of duration of annealing.

Table 1. Values of heat effects at the sample cooled at the rate of $900 \mathrm{~K} / \mathrm{s}$.

\begin{tabular}{|c|c|c|c|c|c|c|c|}
\hline \multicolumn{3}{|c|}{ Devitrification } & \multicolumn{2}{|c|}{$\mathbf{L}_{\text {c.cr. }}, \mathbf{J} / \mathbf{g}$} & \multicolumn{2}{|c|}{$\mathbf{L}_{m}, \mathbf{J} / \mathrm{g}$} & \multirow{2}{*}{$\begin{array}{c}\mathbf{L}_{\mathbf{h} . c r}, \\
\mathbf{J} / \mathbf{g}\end{array}$} \\
\hline $\begin{array}{c}T_{\text {ons, }}, \\
K\end{array}$ & $\mathbf{T}_{\mathbf{g}}, \mathbf{K}$ & $\begin{array}{c}\Delta \mathbf{c}_{\mathrm{p}}, \\
\mathbf{J} /(\mathbf{g} \cdot \mathbf{K})\end{array}$ & $\begin{array}{c}1 \\
\text { peak }\end{array}$ & $\begin{array}{c}2 \\
\text { peak }\end{array}$ & $\begin{array}{c}1 \\
\text { peak }\end{array}$ & $\begin{array}{c}2 \\
\text { peak }\end{array}$ & \\
\hline 785 & 806 & 0.637 & 15 & 98 & 13 & 152 & 164 \\
\hline
\end{tabular}

Microstructure analysis of samples (Fig. 1) received after annealing showed that initially $(\tau=5 \mathrm{~min})$ single faceted crystals of magnetite presumably are formed. At the entire area of metallographic section a thin wall of crystal is formed with the size of cell $0.3-0.5 \mu \mathrm{m}$. It should be noted that increase of annealing duration $(\tau=$ $60 \mathrm{~min}$ ) of amorphous sample results in formation of certain particles in the area close to the surface of larger dendrites with the axes of the second and third order. Closer to the particles border dendrite axes length decreases, phases having in the metallographic section plane the structure in the form of triangles and stars with the size of 5-10 $\mu \mathrm{m}$ form around them. According to the work [7] and based on thermal analysis data viscosity crystallization criterion can be evaluated as

$\alpha=T_{g} / T_{m}$,

where $T_{m}-$ temperature of dissolution of crystalline phases in the melt (1376 K),

defining together with the force of surface tension the capacity of glasses to mass devitrification. Value $\alpha$ calculated by this equation in this case made up 0.6 that shows the inclination of oxide glass under study to surface crystallization. Mechanism of initial formation of crystalline phases is apparently explained by annealing temperature $(1023 \mathrm{~K})$ which is higher than that of cold crystallization. During the heating of a quenched sample from oversaturated silicate phase forming the glass diffusion separation of magnetite and formation of iron silicate phase crystals occurs with a little bit lesser (compared to glass) iron content:

$\mathrm{Fe}_{1+\mathrm{x}} \mathrm{SiO}_{3+\mathrm{x}+\mathrm{y}}=\mathrm{Fe}_{1+\mathrm{x}-3 \mathrm{y} / 4} \mathrm{SiO}_{3+\mathrm{x}}+\mathrm{y} / 4 \mathrm{Fe}_{3} \mathrm{O}_{4}$.

Analysis of sample annealed within $60 \mathrm{~min}$ by X-ray spectral microanalysis (RSMA) in element characteristic radiation showed that the basis of dendrite phase is formed by iron oxides while a basis of glass - iron silicates. The composition of dendrite phases depending on crystal forms is variable, phases in the form of triangles and stars are richer in iron and close to magnetite in terms of composition, and they contain less impurity elements of silicon $(0.9 \%)$ and calcium $(0.2 \%)$ (Fig. 4, Table 2). Copper (0.2-0.7\%) and zinc (2.7-3.7\%) concentration in magnetite are virtually not connected with geometric form of crystals. Silicate phase in terms of composition is close to $\mathrm{Fe}_{1.36} \mathrm{SiO}_{3.36}$, the content of copper reaches $0.8 \%$, and zinc $-4.1 \%$. The presence of sulfur determines formation in the sample of fine bornite phases of nonspherical forms $(1-6 \mu \mathrm{m})$ and larger chalcosine with the size of $15-25 \mu \mathrm{m}$.

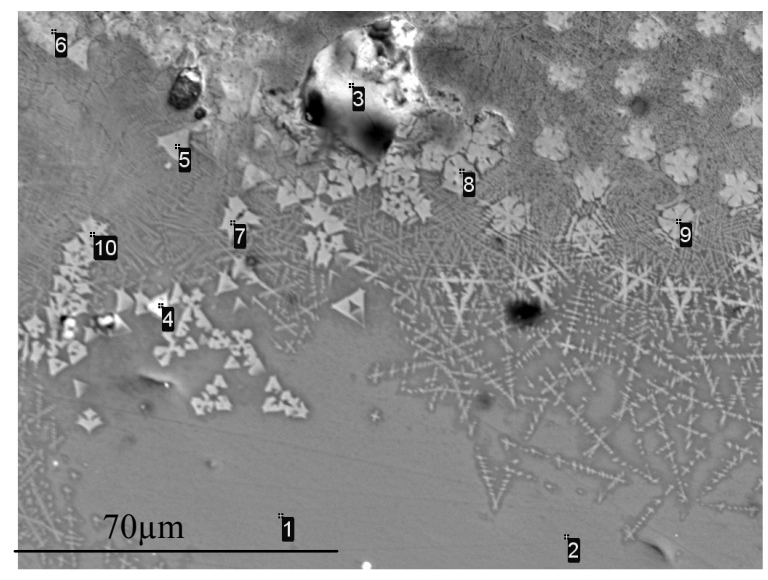

Fig. 4. Microstructure of sample after annealing at $1023 \mathrm{~K}$ within $60 \mathrm{~min}$ and a point of phases local probing.

Table 2. X-ray spectral analysis data: composition of quenched sample annealed at $1023 \mathrm{~K}$ within $60 \mathrm{~min}$ (Fig. 4)

\begin{tabular}{|c|c|c|c|c|c|c|}
\hline \multirow{2}{*}{ № } & \multicolumn{7}{|c|}{ Content, mass, \% } \\
\cline { 2 - 7 } & $\mathbf{S i}$ & $\mathbf{F e}$ & $\mathbf{S}$ & $\mathbf{C u}$ & $\mathbf{Z n}$ & $\mathbf{A l}$ \\
\hline 1 & 14.9 & 40.4 & 0.55 & 0.8 & 3.8 & 2.7 \\
\hline 2 & 14.6 & 41.1 & 0.43 & 0.5 & 4.1 & 2.8 \\
\hline 3 & 0.2 & 3.5 & 21.5 & 76.5 & - & 0.5 \\
\hline 4 & 5.7 & 26.2 & 7.9 & 20.9 & 2.7 & 1.7 \\
\hline 5 & 0.9 & 69.6 & - & 0.4 & 2.7 & 1.9 \\
\hline 6 & 4.1 & 61.9 & 0.26 & 0.6 & 3.7 & 2.0 \\
\hline 7 & 4.9 & 60.7 & 0.08 & 0.2 & 2.6 & 2.8 \\
\hline 8 & 2.3 & 64.5 & 0.09 & 0.7 & 3.8 & 2.2 \\
\hline 9 & 3.1 & 63.3 & - & 0.2 & 3.7 & 2.7 \\
\hline 10 & 2.4 & 64.7 & - & 0.4 & 3.4 & 2.7 \\
\hline
\end{tabular}

\section{Conclusions}

1. It is shown that granulation of iron silicate melts containing more than $30 \% \mathrm{SiO}_{2}$ results in formation of glass. During granules heating devitrification temperatures equal to $806 \mathrm{~K}$, "cold" crystallization temperatures equal to 828 and $878 \mathrm{~K}$, melting temperature equal to $1250 \mathrm{~K}$, and temperature of melt crystallization $1316 \mathrm{~K}$ were determined. Values of thermal capacity change in terms of devitrification as well as heats of phase transitions are calculated.

2. Initial crystallization stages of high iron oxide glass are studied. It is shown that sample annealing at $1023 \mathrm{~K}$ results in initial separation of magnetite in the form of geometric crystals from oversaturated iron-silicate matrix. Diffusion mechanism of magnetite crystals growth is of surface character.

3. Composition of forming phases are determined that allowed to evaluate the impact of crystallization process and to define the forms of stay and dissolubility of nonferrous metals. 


\section{References}

1. A. Karamanov, M. Pelino, J. Non-Crystalline Solids. 281 (2001)

2. E. N. Selivanov, R. I. Gulyaeva, L. Yu. Udoeva, V. V. Belyaev, A. A. Pankratov, Russian Metallurgy (Metally). 4 (2009)

3. E.N. Selivanov, R.I. Gulyaeva, N.I. Selmenskich, Defect and Diffusion Forum, Trans Tech Publications. 297-301 (2010)

4. S.S. Naboytchenko, O.S. Netchiporenko, I.B. Murashova at al.: Non-Ferrous Metal Powders (Metallurgy, Moscow, 1997) [in Russian].

5. O. V. Mazurin, Vitrification (Nauka, Moscow, 1986) [in Russian].

6. K. Biswas, A.D. Sontakke, M. Majumder, K. Annapurna, J. Therm. Anal. Calorim. 101 (2010)

7. G.A. Sycheva, I.G. Polyakova. Composition and properties of metal and slag melts. (Ekaterinburg, 2004) [in Russian]. 